\title{
Maternal health: A reflector for fetal malnutrition
}

\author{
Swati Singh ${ }^{1}$, Mumtaz Sharif ${ }^{2}$, Nikhil Achanta ${ }^{1}$, Neha Jafri ${ }^{3}$ \\ From ${ }^{1}$ Junior Resident, ${ }^{2}$ Associate Professor, ${ }^{3}$ Senior Resident, Department of Pediatrics, D.Y. Patil Medical College, Navi Mumbai, Maharashtra, \\ India
}

Correspondence to: Mumtaz Sharif, B/3, 203, Vighnahar CHS, Opposite Minatai Hospital, Sector 21, Nerul East, Navi Mumbai - 400706 , Maharashtra, India. E-mail: mumtaz23.75@gmail.com

Received - 17 April 2019

Initial Review - 07 May 2019

Accepted - 17 June 2019

\begin{abstract}
Introduction: The high incidence of low birth weight babies in India is due to the neglect of health and education of females, teenage marriages, frequent pregnancies, maternal malnutrition, anemia, and infections. Objective: The objective of his study was to identify the role of various maternal factors such as maternal age, parity, regular antenatal care (ANC) visits, weight, anemia, socioeconomic status, and maternal pre-eclampsia affecting the nutrition of the fetus. Materials and Methods: In this observational study, 500 mother-infant pair recruited, consecutively. A detailed antenatal and postnatal history of the mother was recorded. Information obtained were age, the weight of mother, parity, number of antenatal visits, and maternal hemoglobin $(\mathrm{Hb})$. Newborn taken for the study was weighed and assessed for their nutritional status using the clinical assessment of nutrition score. Results: Of 500 babies, $51.4 \%$ of babies were born to mothers aged $\leq 20$ years; and out of them, $76.5 \%$ of babies had fetal malnutrition. About $45.2 \%$ of babies born to primigravidae mother; of which, $85.9 \%$ had fetal malnutrition (FM). About $54.8 \%$ of babies born to multigravida mothers; of which, $45.3 \%$ had FM. Of $69.2 \%$ of mothers, who had irregular or no ANC, $75.1 \%$ of babies had FM. Mothers with weight $\leq 50 \mathrm{~kg}$ were $45.6 \%$ and $78.9 \%$ of their babies had FM. In $44 \%$ of mothers, $\mathrm{Hb}$ was $\leq 10 \mathrm{~g} \%$ and $91.8 \%$ of babies born to these mothers had FM. Of $48.80 \%$ of babies born to pre-eclamptic babies, $77.5 \%$ of babies had FM. All these maternal factors were statistically significant in their impact on FM $(\mathrm{p}<0.05)$. Conclusion: Maternal nutrition and well-being are essential to bring down the percentage of FM in babies. Proper education not only of the mother but also of society as a whole, recognition of these factors and timely intervention will go a long way not only in improving the quality of life of babies born to such mothers but also in reducing the economic burden on a precariously balanced health-care system.
\end{abstract}

Key words: Clinical assessment of nutrition score, Fetal malnutrition, Maternal factor

$\mathrm{T}$ The incidence of low birth weight (LBW) babies continues to be high in developing countries. A country like India has $30 \%$ incidence of LBW in contrast to $5-7 \%$ in developed countries [1]. Chromosomal abnormalities, congenital infection, affect fetal growth in the uterus, but the majority of factors related to impaired fetal growth are extrinsic factors which can be driven in the mother, placenta, and social environment. The prime attributions of these factors are ascribed to the various socioeconomic and cultural factors, which can be commonly observed in the developing countries. These factors are neglect of health, lack of education of females, teenage marriages, frequent pregnancies, maternal malnutrition, anemia, and infections [2,3]. Malnourished babies born to mothers with any of the above-mentioned indisposition are at higher risk of developing long-term sequelae.

In the present study, comparison was made between various maternal factors that affect the mother and, therefore, fetus, such as maternal age, parity, regular antenatal care (ANC) visits, weight, anemia, socioeconomic status, and maternal pre-eclampsia. Most of the existing studies have focused on the relationship between the above-mentioned factors with weight for age criteria. The present study instead used Clinical Assessment of Nutrition (CAN) [4] score to classify fetal malnutrition (FM).

\section{MATERIALS AND METHODS}

The present study was carried out in the postnatal ward of D.Y. Patil Hospital in Navi Mumbai, India, after taking the prior approval of the Institutional Ethics Committee. This observational study included mothers who delivered term singleton newborns in the hospital. A total of 500 mother-infant pairs were recruited consecutively over a period of 1 year from October 2015 to September 2016. Informed consent was taken from the mothers of the babies satisfying the inclusion criteria, i.e., healthy, term singleton newborns. Mothers of babies with an obvious congenital malformation, preterm newborns ( $<37$ weeks gestation), highrisk babies, and babies admitted in neonatal intensive care unit were excluded from this study.

A detailed antenatal and postnatal history of the mother was recorded. Information obtained were age, the weight of mother, 
parity, number of antenatal visits, maternal weight, hemoglobin $(\mathrm{Hb})$, and blood pressure. Hb levels $<10 \mathrm{~g} \%$ were taken as cutoff for anemia. The babies satisfying the inclusion criteria and their respective mothers were weighed within $24 \mathrm{~h}$ of delivery using an electronic scale. Mothers were classified according to their weights with $\leq 50 \mathrm{~kg}$ considered as underweight and $>50 \mathrm{~kg}$ as appropriate. More than 3 ANCs were deemed appropriate in the present study. Raised blood pressure of $>140 / 90 \mathrm{mmHg}$ after 20 weeks of gestational age was observed twice, $6 \mathrm{~h}$ apart in a pregnant woman in addition to pedal edema and proteinuria was taken as pre-eclampsia [5]. Metcoff's CAN score [4] was used as a standard tool for the nutritional assessment of the babies. A score of $\leq 24$ was used to identify FM.

The sample size of the study population was determined using the standard formula for qualitative analysis. Data were collected on a pro forma designed for the study and the data were analyzed using the SPSS software version 17. Statistical significance was determined using the Chi-square test. Mean and standard deviation of variables such as weight and length were done using Microsoft Excel sheet. The confidence interval was set at 95\% and $\mathrm{p}<0.05$ was considered statistically significant.

\section{RESULTS}

Of the 500 babies studied, $262(52.4 \%)$ were male babies and $238(47.6 \%)$ were female. The incidence of FM in both the sexes was almost equal. In the present study, the incidence of FM was $192(76.5 \%)$ with the maternal age of $<20$ years. With the maternal age of $>20$ years, the incidence of FM was 140 (56.2\%). With $\mathrm{p}<0.00001$, the comparison between the two groups was statistically significant. Maternal parity has shown a significant association with FM. The number of babies with FM was more
$202(86 \%)$ with primigravida in comparison to multigravida $72(49.05 \%)$ mother $(\mathrm{p}<0.00001)$.

A significant relation of regular ANC visits with FM was observed. Mothers with no/irregular ANC gave birth more number of babies with FM(260,75.14\%) as compared to $72(46.75 \%)$ babies with FM with regular ANC visits from the mothers $(\mathrm{p}<0.00001)$. Maternal weight had a significant relation $(\mathrm{p}<0.00001)$ with FM. The number of babies with FM was $180(78.94 \%)$ in mothers weighing $<50 \mathrm{~kg}$ in comparison to $152(55.88 \%)$ with maternal weight $>50 \mathrm{~kg}$. Anemia and pre-eclampsia are major maternal risk factors significantly associated with FM $(\mathrm{p}<0.00001$ for both). Babies with FM were 202 (91.84\%) with mother having anemia $(\mathrm{Hb}<10 \mathrm{~g} \%)$ in comparison to $130(46.4 \%)$ with mothers having no anemia $(\mathrm{Hb}>10 \mathrm{~g} \%)$. Babies with FM were $62(77.5 \%)$ in mothers having pre-eclampsia as compared to $270(64.2 \%)$ in mothers having no pre-eclampsia. These results are summarized in Table 1.

\section{DISCUSSION}

FM results from intrauterine difficulties in the baby and may lead to perinatal problems [6]. Babies with FM have been found to possess significantly lower intelligence quotient and performance than well-nourished infants as reported by cohort studies done years after delivery $[7,8]$. FM is assessed using CAN score which is based on nine superficial detectable signs of malnutrition in the newborn, in which a score of $\leq 24$ is used to define malnutrition [4]. CAN score classified babies as malnourished or well-nourished based on their nutritional status so that malnourished infants can be given special care.

It is a well-known fact that maternal adversities are important causative factors of fetal underdevelopment and LBW [2,3,9].

Table 1: Comparison between maternal factors and fetal malnutrition

\begin{tabular}{|c|c|c|c|c|}
\hline \multirow[t]{2}{*}{ Parameters } & \multicolumn{2}{|c|}{ Clinical assessment of nutrition score (\%) } & \multirow[t]{2}{*}{ Total } & \multirow[t]{2}{*}{ p-value } \\
\hline & $\leq 24$ & $>25$ & & \\
\hline \multicolumn{5}{|c|}{ Maternal age (years) } \\
\hline$<20$ & $192(76.5)$ & $59(23.5)$ & 251 & $<0.00001$ \\
\hline$>20$ & $140(56.2)$ & $109(43.8)$ & 249 & \\
\hline \multicolumn{5}{|l|}{ Parity } \\
\hline Primigravida & $202(86)$ & $33(14)$ & 235 & $<0.00001$ \\
\hline Multigravida & $130(49)$ & $135(51)$ & 265 & \\
\hline \multicolumn{5}{|l|}{ ANC visits } \\
\hline$<3$ & $260(75.1)$ & $86(24.9)$ & 346 & $<0.00001$ \\
\hline$>3$ & $72(46.8)$ & $82(53.2)$ & 154 & \\
\hline \multicolumn{5}{|c|}{ Maternal hemoglobin } \\
\hline$<10$ & $202(91.8)$ & $18(8.2)$ & 220 & $<0.00001$ \\
\hline$>10$ & $130(46.4)$ & $150(53.6)$ & 280 & \\
\hline \multicolumn{5}{|l|}{ Mother's weight } \\
\hline$<50$ & $180(79)$ & $48(21)$ & 228 & $<0.00001$ \\
\hline$>50$ & $152(55.9)$ & $120(44.1)$ & 272 & \\
\hline \multicolumn{5}{|l|}{ Pre-eclampsia } \\
\hline Yes & $62(77.5)$ & $18(22.5)$ & 80 & $<0.02$ \\
\hline No & $270(64.3)$ & $150(35.7)$ & 420 & \\
\hline
\end{tabular}


A concrete relationship between maternal health and FM has been aimed. In the present study, the incidence of FM was $66.4 \%$, which is similar to a study by Amarendra and Yoganand using CAN score, $68.4 \%$ of babies were categorized as malnourished which was comparable to the present study [10]. This difference in the values could be attributed to the fact that maternal malnutrition and poor ANC are encountered more frequently in developing countries.

The present study showed a significant relationship between maternal weight and incidence of FM babies (78.9\% vs. 55.8\% in mothers weighing $<50 \mathrm{~kg}$ and $>50 \mathrm{~kg}$, respectively) which is similar to the results observed by Ginner et al. who reported similar observations ( $84.5 \%$ vs. $55.7 \%$ FM in mothers weighing $<50 \mathrm{~kg}$ and $>50 \mathrm{~kg}$, respectively) [11]. Another Indian study had reported that $58.05 \%$ of babies born to mothers with weight $<50 \mathrm{~kg}$ were LBW, which was statistically significant [12]. Kandhasamy and Singh, in another study done in India, also reported a significant correlation between maternal weight $<45 \mathrm{~kg}$ and the incidence of LBW [13].

It has been observed mothers with relatively short heights and less body weight had higher probability of producing a small baby. Maternal height of $<145 \mathrm{~cm}$ and weight $<40 \mathrm{~kg}$ are considered as maternal high-risk factors adversely affecting fetal growth. Small newborn female children of these mothers may grow up to become small girls due to altered growth potential. They grow up with less height and weight alongside a compromised reproductive efficiency, the cycle of which further continues.

Maternal age was also found to be significantly associated with the incidence of malnourished babies which was $76.5 \%$ in mothers aged $<20$ years versus $56.2 \%$ with maternal age $>20$ years. This is similar to results found in another Indian study by Joshi et al. which showed that young mothers aged $<20$ years have more LBW babies (53.45\%), compared with mothers aged $>20$ years (30.1\%) [14]. According to the WHO, adolescent mothers have more chances of giving birth to LBW babies as they are still developing and growing, and therefore, mother and offspring may compete for the supply of nutrients [15].

On the other hand, if the maternal age is more than 35 years, there are higher chances of complication and morbidity. Data analysis from the present study indicates that FM was more common with primigravidae as compared to multigravidae $(85 \%$ and $49 \%$, respectively). Similarly, Varahala et al. have reported $63.64 \%$ of LBW in primigravidae mothers and $41.98 \%$ in multigravidae [16]. Iltaf et al. also showed that there is a high risk of LBW in primigravida and mothers with malnutrition [17]. On the other hand, in a study done by Josiah et al., in Nigeria, FM occurred frequently in babies of primiparous mothers (21.7\%), but there was no significant relationship in the occurrence of LBW due to parity [18].

A significant correlation between maternal disease states such as anemia and pre-eclampsia and the incidence of FM was also observed. The incidence of FM was found to be almost double in anemic mothers as compared to non-anemic ones $(91.8 \%$ and $46.4 \%$, respectively). This occurs as a result of low availability of oxygen due to severe anemia. Furthermore, pre-eclamptic mothers had more babies with FM (77.5\%) as opposed to normotensive mothers (64\%). This could be related to the reduction in uteroplacental perfusion with chronic hypertension. Similar results were reported by Kushwaha et al., who noted that the prevalence of FM among anemic mothers was $68 \%$ and nonanemic mothers was $34 \%$, and the same in pre-eclamptic mothers was $70 \%$, and normotensive mothers was $34 \%$ [19].

Another factor that significantly influenced the incidence of FM observed in the present study was regular ANC visits. The incidence of FM in babies was $75.1 \%$ whose mothers did not attend antenatal clinics. Prenatal care is the most important tool available to health-care providers to detect modifiable risk factors for FM (infections, micronutrients deficiency). An Indian study by Joshi et al. also suggests that there is a significant relationship between antenatal visits and the outcome of the newborn. They found that the incidence of LBW was $61.76 \%$ and $46.57 \%$ who had no or inadequate visit to the ANC [14]. Another study supporting the findings of the present study by Idris et al. who found that the incidence of LBW was $56.2 \%$ with no antenatal visits and $49.4 \%$ with inadequate visits [20]. If the ANC visits are on regular basis then the mother is instructed about the nutrition, supplements, and immunization, weight is monitored and all the precautions are also taken so that it does not tend toward high-risk pregnancy. A similar study done in Nepal by Khanal et al. said that ANC visits have a strong impact on fetal nutrition and outcome [21]. The limitations in the present are the small study population; a larger study population might have provided deeper understanding of the role of maternal risks factors on the overall outcome of FM.

\section{CONCLUSION}

The above study depicts that maternal factors such as maternal age, weight and $\mathrm{Hb}$, parity, ANC visits, and pre-eclamptic status can affect fetal nutrition in utero. Therefore, proper maternal care and well-being are essential to bring down the percentage of FM in babies. Proper education not only of the mother but also of society as a whole, recognition of these factors and timely intervention will go a long way not only in improving the quality of life of babies born to such mothers but also in reducing the economic burden on a precariously balanced health-care system.

\section{ACKNOWLEDGMENT}

We are thankful to the Department of Paediatrics and Obstetrics and Gynaecology of our institute for allowing us to conduct this study.

\section{REFERENCES}

1. WHO, UNICEF. Low Birth Weight: Country, Regional and Global Estimates. Geneva: WHO, UNICEF; 2004. p. 13.

2. Frederick IO, Willams MA, Sales AE, Martin DP, Killien M. Pre-pregnancy body mass index, gestational weight gain, and other maternal characteristics in relation to infant birth weight. Matern Child Health J 2007;12:557-67.

3. Steer PJ, Little MP, Kold-Jansen T, Chapple J, Elliott P. Maternal blood 
pressure in pregnancy, birth weight, and perinatal mortality in first births: Prospective study. BMJ 2004;329:1312-8.

4. Metcoff J. Clinical assessment of nutritional status at birth. Fetal malnutrition and SGA are not synonymous. Pediatr Clin North Am 1994;41:875-91.

5. Roberts JM, Cooper DW. Pathogenesis and genetics of pre-eclampsia. Lancet 2001;357:53-6.

6. Deodhar J, Jarad R. Study of the prevalence of and high risk factors for fetal malnutrition in term newborns. Ann Trop Paediatr 1999;19:273-7.

7. Fall $\mathrm{CH}$. Fetal malnutrition and long-term outcomes. Nestle Nutr Inst Workshop Ser 2013;74:11-25.

8. Jayant D, Rajkumar J. Study of the prevalence and high risk factors for fetal malnutrition in term newborns. Ann Trop Paediatr 1999;19:273-7.

9. Singh G, Chouhan R, Sidhu K. Maternal factors for low birth weight babies. Med J Armed Forces India 2009;65:10-2.

10. Amarendra M, Yoganand M. Comparison of clinical assessment of nutritional status (CAN) score with other methods in the assessment of fetal malnutrition. Int J Contemp Pediatr 2017;4:713-8.

11. Ginner K, Fenercioglui KA, Asiye N. Catch up growth in fetal malnourished term infants. J Perinat Med 2002;30:411-5.

12. Ali N, Majhi B. Study on socio cultural and maternal factors in relation to lbw babies and their immediate outcome. J Med Sci Clin Res 2017;5:30995-9.

13. Kandhasamy K, Singh Z. Determinants of low birth weight in a rural area of Tamil Nadu, India: A case control study. Int J Med Sci Public Health 2015;4:376-80.

14. Joshi HS, Srivastava PC, Agnihotri AK, Joshi MC, Chandra S, Mahajan V. Risk factors for low birth weight babies and its medico-legal significance. J Indian Acad Forensic Med 2010;32:971-3.

15. World Health Organisation. Bridging the Gaps: Report of the Director General. The World Health Report. Geneva: World Health Organisation;
1995. p. 5-6.

16. Varahala AM, Pathuri NK, Chidugulla SK. Influence of maternal factors on foetal malnutrition using can score assessment a tertiary care centre experience. J Evol Med Dent Sci 2018;7:1433-8.

17. Iltaf G, Shahid B, Khan MI. Incidence and associated risk factors of low birth weight babies born in shaikh khalifa bin zayad al-nayan hospital Muzaffarabad, Azad Jammu and Kashmir. Pak J Med Sci 2017;33:626-30.

18. Josiah AE, Opara PI, Nte AR. Prevalence of and risk factors for fetal malnutrition in term babies delivered at a tertiary hospital in Southern Nigeria. J Clin Neonatol 2018;7:31-7.

19. Kushwaha KP, Sing YD, Bhatia VM, Yogita G. Clinical assessment of nutritional status (CANS) in term newborns and its relation to outcome in neonatal period. J Neonatol 2004;18:55-9.

20. Idris MZ, Gupta A, Mohan U, Srivastava AK, Das V. Maternal health and low birth weight among institutional deliveries. Indian J Community Med 2000;25:156-60.

21. Khanal V, Zhao Y, Sauer K. Role of antenatal care and iron supplementation during pregnancy in preventing low birth weight in Nepal: Comparison of national surveys 2006 and 2011. Arch Public Health 2014;72:2049-3258.

Funding: None; Conflict of Interest: None Stated.

How to cite this article: Singh S, Sharif M, Achanta N, Jafri N. Maternal health: A reflector for fetal malnutrition. Indian J Child Health. 2019; 6(7):353-356.

Doi: 10.32677/IJCH.2019.v06.i07.006 